\title{
Sociodemographic variations in the contribution of secondary drug prevention to stroke survival at middle and older ages: cohort study
}

\author{
Rosalind Raine, professor of health care evaluation, ${ }^{1}$ Wun Wong, honorary research fellow, ${ }^{1}$ Gareth Ambler, \\ lecturer, ${ }^{2}$ Sarah Hardoon, statistician, ${ }^{3}$ Irene Petersen, statistician, ${ }^{3}$ Richard Morris, reader, ${ }^{3}$ Mel Bartley, \\ professor of medical sociology, ${ }^{1}$ David Blane, professor of medical sociology ${ }^{4}$
}

$\overline{1}$ Department of Epidemiology and Public Health, University College London, London WC1E 6BT

${ }^{2}$ Department of Statistical Science, University College London and University College London/Hospital Biomedical Research Unit

${ }^{3}$ Department of Primary Care and Population Health, Royal Free and University Medical School, London ${ }^{4}$ Department of Primary Care and Social Medicine, Imperial College London

Correspondence to: $\mathrm{R}$ Raine r.raine@ucl.ac.uk

Cite this as: $B M J$ 2009;338:b1279 doi:10.1136/bmj.b1279

\section{ABSTRACT}

Objectives To determine the extent to which secondary drug prevention for patients with stroke in routine primary care varies by sex, age, and socioeconomic circumstances, and to quantify the effect of secondary drug prevention on one year mortality by sociodemographic group.

Design Cohort study using individual patient data from the health improvement network primary care database. Setting England.

Participants 12830 patients aged 50 or more years from 113 general practices who had a stroke between 1995 and 2005 and who survived the first 30 days after the stroke.

Main outcome measures Multivariable associations between odds of receiving secondary prevention after a stroke, and sex, age group, and socioeconomic circumstances; hazard ratios for all cause mortality from 31 days after the stroke and within the first year among patients receiving treatment and by social group; and probabilities of one year mortality for social factors of interest and treatment.

Results Only $25.6 \%$ of men and $20.8 \%$ of women received secondary prevention. Receipt of secondary prevention did not vary by socioeconomic circumstances or by sex. Older patients were, however, substantially less likely to receive treatment. The adjusted odds ratio for $80-89$ year olds compared with 50-59 year olds was 0.53 (95\% confidence interval 0.41 to 0.69 ). This was because older people were less likely to receive lipid lowering drugs-for example, the adjusted odds ratio for $80-89$ year olds compared with 50-59 year olds was 0.44 (95\% confidence interval 0.33 to 0.59 ). Secondary prevention was associated with a $50 \%$ reduction in mortality risk (adjusted hazard ratio $0.50,95 \%$ confidence interval 0.42 to 59). On average, mortality within the first year was $5.7 \%$ for patients receiving treatment compared with $11.1 \%$ for patients not receiving treatment. There was little evidence that the effect of treatment differed between the social groups examined.

Conclusion Under-treatment among older people with stroke in routine primary care cannot be justified given the lack of evidence on variations in effectiveness of treatment by age.

\section{INTRODUCTION}

The contribution of medical care to population health has been a topic of scientific debate for years. McKeown's work sparked controversy, but there is agreement with his claim that clinical interventions played little part in the decline in mortality before the mid-20th century. ${ }^{1}$ Major advances in medical technology during the 20th century stimulated a re-examination of the role of health care in population health. International studies have focused on coronary heart disease. These suggest that $50-75 \%$ of the reductions in deaths from cardiac causes can be attributed to improvements in the major risk factors at population level, particularly smoking but also cholesterol levels and blood pressure, ${ }^{2-5}$ whereas the remaining $25-50 \%$ can be attributed to medical intervention. Among patients with established coronary heart disease, nearly $78 \%$ of prevented or postponed deaths are attributable to medical or surgical intervention. ${ }^{6}$

Outstanding matters remain. The first is whether the contribution of health care to survival is similar across population subgroups. In England and Wales substantial improvements in mortality have occurred among middle aged and older people (aged 50-69) over the second half of the 20th century, particularly during the final decades. ${ }^{7}$ During this period only modest improvements in mortality occurred among 20-40 year olds but substantial improvements occurred among 50-79 year olds. Thus between 1981 and 2000, life expectancy at age 50 increased by 3 . 8 years among men and 2.6 years among women. ${ }^{8}$ It is particularly relevant to examine the impact of medical treatment on health outcomes in older people within the context of evidence that elderly people may be less likely to receive medical interventions, perhaps because of uncertainties over trade-offs between risks and benefit. ${ }^{9-11}$ There is also widespread evidence that socially disadvantaged people and women are less likely to receive treatments for 
cardiovascular disease compared with their affluent and male counterparts. ${ }^{12}{ }^{13}$ Variations in use of health care across social groups are difficult to justify if treatment associated improvements in mortality are similar across these groups.

Secondly, it cannot be assumed that the contribution of health care to improvements in death from coronary heart disease applies to all the major causes of death. Stroke is the second most common cause of death after coronary heart disease in developed countries ${ }^{14}$ and $80 \%$ of cases occur in over $64 \mathrm{~s} .{ }^{15}$ It shares many of the risk factors with coronary heart disease yet it is associated with a slower rate of decline in mortality. ${ }^{7}$ This may be because stroke is a syndrome in which the broadest subcategories are cerebral infarct (about $80 \%$ of cases and more common with age) and cerebral haemorrhage. ${ }^{1617}$ Whereas cerebral infarct and coronary heart disease are likely to have a common cause, the evidence suggests that cerebral haemorrhage has different causes. ${ }^{18}$ Thus, in common with coronary heart disease, the serum cholesterol level is positively associated with cerebral infarct but is inversely associated with haemorrhagic stroke, ${ }^{19}$ and there are noticeable differences in the pooled relative risks for the effect of smoking on cerebral infarct $(1.92)^{20}$ and cerebral haemorrhage (1.06). ${ }^{21}$ It is possible that exposures in early life could be more important in cerebral haemorrhage. ${ }^{18}$ It is therefore plausible to suggest that the balance between the contribution of health care compared with behavioural interventions to health outcomes may be different for stroke compared with coronary heart disease. Estimates of treatment effects for individual interventions for stroke can be obtained from randomised trials, but beneficial effects tend to be lower in routine clinical practice and it cannot be assumed that the effectiveness of recommended combinations of treatment are additive and independent. Estimations of treatment effects using observational data from routine care overcome these limitations.

We analysed the contribution of secondary drug prevention to stroke survival among adults aged 50 or more between 1995 and 2005 using a national primary care dataset for England. We determined the extent to which secondary prevention for stroke varies by sex, age, and socioeconomic circumstances; whether the association between secondary prevention and one year mortality after stroke varies between social groups; and the effect of secondary prevention on one year mortality by sociodemographic group.

\section{METHODS}

We examined individual patient data from primary care using the health improvement network database. ${ }^{22}$ This database comprises over 15 years of individual level medical and therapeutic data on 1.99 million patients from 253 general practices across England.

The health improvement network database is similar to the general practice research database, and about half of practices in the health improvement network database also report to the general practice research database. ${ }^{23}$ However the health improvement network database has the advantage of including an indicator of socioeconomic circumstances associated with patients' postcodes. Patients' socioeconomic circumstances are determined by the area level Townsend index of deprivation. $^{24}$ The index is based on four variables taken from the 2001 census and available at the output area level (about 150 households). These variables (household unemployment, overcrowding, owner occupation, and car ownership) combine to form an overall score. The higher the index score, the more deprived and disadvantaged an area is judged to be. Scores for the ward of residence of each patient are ranked and divided into fifths ( 1 for least deprived, 5 for most deprived). Each patient is then assigned a Townsend fifth score as a measure of their socioeconomic circumstances.

\section{Study design}

We identified practices that had contributed computerised data for at least five years between 1995 and 2005. We included data only from practices that

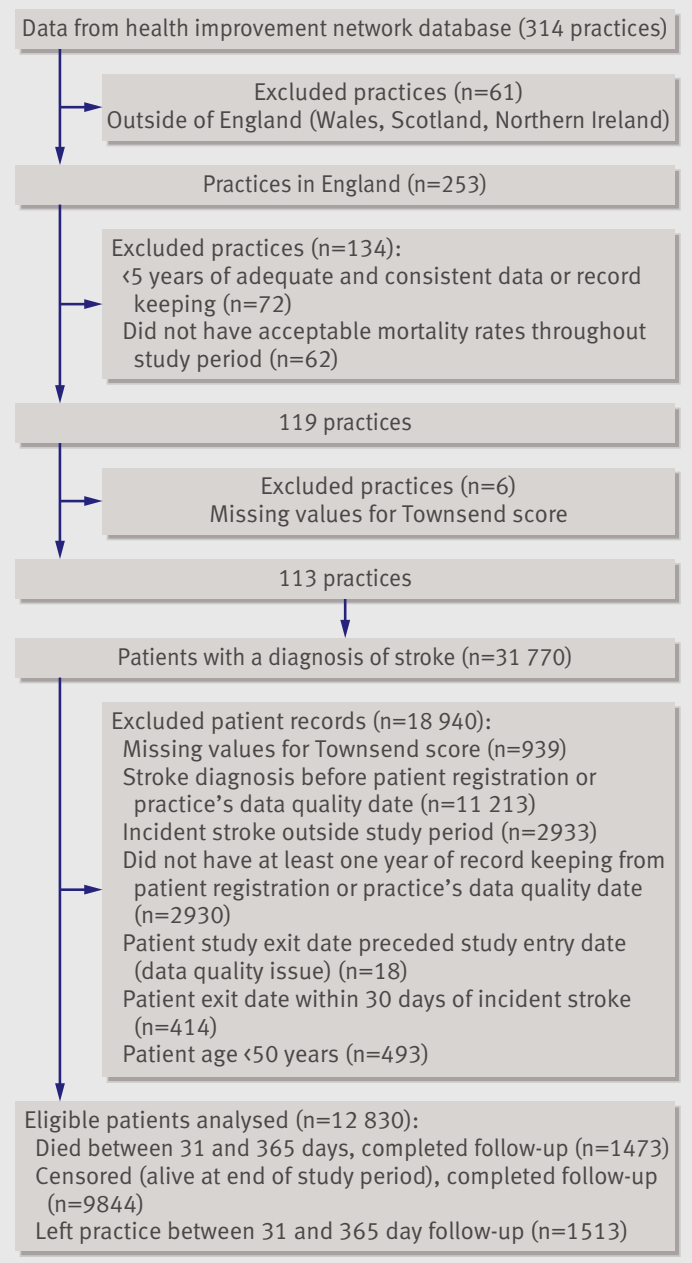

Steps taken in selecting practices contributing data to health improvement network database and patient records for analysis. *Patients with missing data on age. Data on sex were excluded before data extract was received 
Table 1|Odds ratio for association between secondary drug prevention and sex, Townsend fifth, and age

\begin{tabular}{|c|c|c|c|c|c|c|}
\hline \multirow[b]{2}{*}{ Variable } & \multirow{2}{*}{$\begin{array}{c}\text { No of } \\
\text { patients }\end{array}$} & \multirow{2}{*}{$\begin{array}{l}\text { No }(\%) \text { of patients } \\
\text { receiving secondary } \\
\text { drug prevention* }\end{array}$} & \multicolumn{2}{|c|}{ Univariable model } & \multicolumn{2}{|c|}{ Multivariable model $†$} \\
\hline & & & Odds ratio $(95 \% \mathrm{Cl})$ & P value $\ddagger$ & Odds ratio $(95 \% \mathrm{Cl})$ & P valuef \\
\hline Men & 6228 & $1594(25.6)$ & 1 & \multirow{2}{*}{$<0.001$} & 1 & \multirow{2}{*}{0.07} \\
\hline Women & 6602 & $1372(20.8)$ & $0.76(0.70$ to 0.84$)$ & & 0.90 (0.80 to 1.01$)$ & \\
\hline \multicolumn{7}{|l|}{ Townsend fifth: } \\
\hline First (least deprived) & 3159 & $748(23.7)$ & 1 & \multirow{5}{*}{0.36} & 1 & \multirow{5}{*}{0.44} \\
\hline Second & 2829 & 677 (23.9) & 1.01 (0.86 to 1.19$)$ & & 1.04 (0.88 to 1.23$)$ & \\
\hline Third & 2719 & $590(21.7)$ & 0.89 (0.75 to 1.06$)$ & & $0.92(0.78$ to 1.10$)$ & \\
\hline Fourth & 2432 & $546(22.5)$ & 0.93 (0.74 to 1.17$)$ & & 0.94 (0.73 to 1.21$)$ & \\
\hline Fifth (most deprived) & 1691 & $405(24.0)$ & 1.02 (0.78 to 1.32$)$ & & 1.01 (0.76 to 1.34$)$ & \\
\hline \multicolumn{7}{|l|}{ Age group: } \\
\hline $50-59$ & 1639 & $432(26.4)$ & 1 & \multirow{5}{*}{$<0.001$} & 1 & \multirow{5}{*}{$<0.001$} \\
\hline $60-69$ & 2749 & $820(29.8)$ & 1.19 (1.00 to 1.42$)$ & & 1.19 (1.00 to 1.42$)$ & \\
\hline $70-79$ & 4319 & $1155(26.7)$ & 1.02 (0.85 to 1.22$)$ & & 1.03 (0.86 to 1.24$)$ & \\
\hline $80-89$ & 3387 & $528(15.6)$ & 0.52 (0.40 to 0.66$)$ & & 0.53 (0.41 to 0.69$)$ & \\
\hline$\geq 90$ & 736 & $31(4.2)$ & 0.12 (0.08 to 0.19$)$ & & $0.13(0.08$ to 0.21$)$ & \\
\hline
\end{tabular}

Standard errors adjusted for clustering (113 practices); $n=12830$.

* Secondary drug prevention prescribed within 0-90 days of incident stroke.

$\dagger$ Each risk factor (sex, Townsend fifth, age group) adjusted for other factors. $\ddagger$ Wald test.

consistently recorded at least one medical record, one additional health data record (for example, a blood pressure measurement), and at least two prescriptions on average for each patient a year. This ensured inclusion of practices that fully used their computer system for consultations. We also restricted our sample to practices with acceptable mortality (based on national data and the practice's demographic profile) throughout the 11 year study period. ${ }^{25}$ The age, sex, and deprivation fifths of included and excluded patients were similar (see web extra table A).

We confined our analyses to patients who were aged 50 or more and who had a diagnosis of incident stroke recorded between 1995 and 2005. To ensure that only patients with incident stroke were examined, we excluded patients with a stroke before 1995 and included only patients with at least one year of strokefree data before the date of the stroke. Overall we excluded 1047 patients because they did not meet the study inclusion criteria or had missing data on Townsend fifths.

The Read code classification scheme is used to code medical diagnoses in the health improvement network database. ${ }^{26}$ We included patients with codes for unspecified stroke, ischaemic (thrombotic or embolic) stroke, subarachnoid haemorrhage, and intracerebral haemorrhage.

UK clinical guidelines for the secondary prevention of stroke in primary care recommend appropriate drug combinations for ischaemic and haemorrhagic stroke. ${ }^{27}$ These state that patients with high blood pressure (systolic blood pressure $>140 \mathrm{~mm} \mathrm{Hg}$, diastolic blood pressure $>85 \mathrm{~mm} \mathrm{Hg}$ ) should receive antihypertensives. In addition, patients with ischaemic stroke should be given antithrombotics and lipid lowering drugs if their total cholesterol level is greater than $3.5 \mathrm{mmol} / \mathrm{l}$. Recent evidence suggests that the benefits of reducing blood pressure and cholesterol levels are irrespective of their baseline levels. ${ }^{2829}$ Furthermore, $70 \%$ of men and $84 \%$ of women aged over 50 have high total cholesterol levels $(>5 \mathrm{mmol} / \mathrm{l}),{ }^{30}$ so most, if not all, patients with ischaemic stroke would be eligible to receive lipid lowering drugs and antihypertensives. As this evidence was available only for the latter part of the study period we designed two sets of analyses. Firstly, we assumed that all patients with ischaemic stroke were eligible to receive antihypertensives and lipid lowering drugs, as suggested by recent evidence (in addition to antithrombotics). In the second analysis we restricted the sample to patients eligible to receive antihypertensives, as defined by the guidelines. We did not restrict the sample on the basis of cholesterol levels because of our experience of inconsistency in data entry on this variable in the health improvement network database.

Drugs in the health improvement network dataset are assigned codes from the British National Formulary. ${ }^{31} \mathrm{We}$ therefore used these codes to identify all blood pressure lowering drugs, lipid lowering drugs, and antithrombotics. Drugs selected for analysis were lipid regulators, antithrombotics (antiplatelets or anticoagulants), and antihypertensives, including diuretics, $\beta$ blockers, angiotensin converting enzyme inhibitors, calcium channel blockers, $\alpha$ adrenoceptor blockers, and adrenergics.

We defined secondary drug prevention as being prescribed either antihypertensives plus lipid lowering drugs plus antithrombotics or antihypertensives plus lipid lowering drugs.

We assumed that prescriptions provided between 0 and 90 days from the initial date of the stroke diagnosis were prescribed for the event. This period was chosen because once discharged from hospital, patients may be given prescriptions by the hospital pharmacy but 
repeat prescriptions would come from primary care. We also had to take account of the drugs being prescribed for conditions other than stroke. To increase the likelihood that the treatment was related to the stroke event we chose a cut-off point of 90 days. The treatment period began immediately after the stroke to ensure that we included all secondary prevention provided within primary care.

Lipid lowering drugs are contraindicated in patients with active liver disease; antiplatelets are contraindicated in patients with severe liver disease, peptic ulcers, and taking anticoagulants; $\beta$ blockers are contraindicated in patients with asthma or chronic obstructive pulmonary disease; certain antihypertensives (particularly angiotensin converting enzyme inhibitors) may be contraindicated or cause complications in patients with chronic renal disease. ${ }^{32}$ We carried out sensitivity analyses after adjustment for evidence of liver disease only (Read codes A7, 44D, J60-J63, 43B, ZV02B, ZV02C) at any time before the stroke diagnosis until 90 days from the date of diagnosis. We did not adjust analyses for asthma, chronic obstructive pulmonary disease, or chronic renal disease because the availability of several classes of antihypertensives allows alternative drugs to be prescribed, as recommended in national guidance. ${ }^{33}$ It was unnecessary to adjust for those conditions for which antiplatelets are contraindicated because our definition of secondary prevention took account of the fact that these drugs might be contraindicated. Finally, we did not adjust for coronary artery disease because of the high colinearity between drugs used for secondary prevention of stroke and those used for coronary artery disease.

Patients who died within 30 days of a stroke were not included in the analyses because most (85-90\%) patients with stroke were admitted to hospital ${ }^{34}$ for a mean of 30 days during the period of study. ${ }^{35}$ This exclusion criterion allowed us to examine the association between mortality and treatment provided by primary care. Our discussion of mortality within the first year assumes that the patient survived the first 30 days.

Smoking has a potential confounding effect between the social factors measured and stroke mortality. Patients' smoking status was defined according to their closest record to the date of stroke. We categorised patients whose smoking status was recorded at any point before to one year after the diagnosis of incident stroke into several groups: smoker, non-smoker, former smoker before stroke, and former smoker after stroke. We created a binary smoking variable: current smoker at stroke date (including former smoker after stroke) compared with not current smoker (including non-smoker and former smoker before stroke).

We used registration data to identify patients who died (all causes). Patient time was calculated from the 31 days after the date of the first record of the stroke to the date of death, the date that the patient left practice, the last data collection from the practice, or end of the study period, whichever came first.

\section{Statistical analysis}

To investigate univariable and multivariable associations between the odds of receiving secondary drug prevention and sex, age group, and deprivation fifth (socioeconomic circumstances), we undertook logistic regression with standard errors adjusted for clustering by general practice. In the multivariable model we adjusted each factor for the other factors examined (sex, age group, and Townsend fifth). A lower than expected proportion of patients were smokers suggesting some misclassification (for example, smokers who said they were non-smokers). As this could introduce bias we excluded the variable "smoking status" in the main analyses but included it in secondary analyses. To further examine the association between patient characteristics and appropriate treatment we developed three further regression models with the outcome variable secondary prevention replaced, respectively, by lipid lowering drugs, antihypertensives, and antithrombotics (all yes or no). In view of the sharp rise in the use of lipid lowering drugs during the study period, we also investigated whether the associations for use of lipid lowering drugs changed over time by fitting models with a dichotomous time variable (1995-9, 2000-5) and the relevant interaction terms.

We applied the Cox proportional hazard model to investigate univariable and multivariable associations between one year mortality and sex, age group, socioeconomic circumstances, and secondary prevention, adjusted for clustering by general practice. In each multivariable model each factor was adjusted for all the other factors examined. The smoking status variable was included in secondary analyses. We created and tested interaction terms between treatment and the other covariates to investigate potential differential treatment associations. The Wald test was used to test for statistical significance. We checked the proportional hazards assumption using Schoenfeld residuals. We used Stata 9.2 for all analyses.

To quantify the effect of secondary prevention on mortality we evaluated the probabilities of mortality within the first year for those social factors of interest (adjusting for the other social factors) and treatment. We repeated the analyses having restricted the sample to patients with blood pressure records and who were eligible to receive antihypertensives.

Sensitivity analyses were done by increasing the prescription period to 365 days because some, particularly elderly, patients may stay in hospital for long periods after stroke. We repeated the analyses adjusted for the presence of liver disease. When we examined the association between patient characteristics and drug treatment, only the model for lipid lowering drugs was adjusted for liver disease.

\section{RESULTS}

In total, 12830 patients from 113 practices across England were included in the study (figure): $11202(87.3 \%)$ had a diagnosis of unspecified stroke, 1019 (7.9\%) of ischaemic stroke, $351(2.7 \%)$ of intracerebral haemorrhage, and $258(2 \%)$ of subarachnoid haemorrhage. 
Because of the high proportion of strokes classed as unspecified it was not possible to distinguish those patients with ischaemic stroke for whom antithrombotic and lipid lowering therapy would be appropriate. As studies have reported that most strokes are ischaemic ${ }^{17}$ the analyses assume that all patients were eligible to receive antihypertensives and lipid lowering drugs. The results of these analyses are illustrated in the tables. In addition we have provided results that were limited to the $6820(53.2 \%)$ patients eligible to receive antihypertensives $(860$ patients were excluded because they were normotensive and 5150 were excluded because they had no blood pressure recorded). When the analyses were adjusted for smoking status, the $11791(91.9 \%)$ patients with a record for smoking status were included, of whom 1989 (16.9\%) were current smokers. Overall, 221 (1.7\%) patients had a record of liver disease.

Variation in secondary prevention by sex, age group, and deprivation

Univariable analyses (table 1) indicated that men were more likely to receive secondary prevention than women $(25.6 \%$ of men $v 20.8 \%$ of women). The odds of receiving secondary prevention decreased for patients aged over $80: 26.4 \%$ of patients aged 50-59 received treatment compared with $15.6 \%$ of patients aged $80-89$ and $4.2 \%$ aged 90 or more. The proportions of patients receiving treatment in each Townsend fifth were similar, ranging from $21.7 \%$ to $24.0 \%$.

The differences in the proportions receiving treatment between the age groups persisted in multivariable analyses. In particular, the odds for receiving treatment decreased for the over 80s. Compared with patients aged 50-59 the odds of receiving treatment for those aged 80-89 was 0.53 (95\% confidence interval 0.41 to 0.69 ) and for those aged 90 or more was 0.13 (0.08 to 0.21$)$. After adjustment for age and deprivation, weak evidence showed an association between sex and receipt of treatment $(0.90,0.80$ to 1.01 , $\mathrm{P}=0.07)$ and no evidence of variation between Townsend fifths.

The findings were not changed by adjusting for smoking status (see web extra table C) or liver disease (see web extra table F) or by restricting the analysis to patients eligible to receive antihypertensives. Expanding the prescription period led to the identification of 797 new cases receiving secondary drug prevention, with similar proportional increases in cases for each age group. This did not alter the findings.

Overall, $32 \%$ of men and $25.7 \%$ of women received lipid lowering drugs, just over $60 \%$ of both sexes received antihypertensives, and $62.3 \%$ of men and $60.4 \%$ of women received antithrombotics (see web extra table B). The odds of being prescribed individual drugs varied by age group. There was also some evidence of variation by sex (table 2). Thus there was strong evidence of a lower probability of receiving lipid lowering drugs for the over 80s. Compared with patients aged 50-59 the odds for patients aged 80-89 receiving treatment was $0.44(95 \%$ confidence interval 0.33 to 0.59 ) and for those aged 90 or more was 0.12 (0.08 to 0.19 ). These results were not affected by adjustment for liver disease (see web extra table $\mathrm{G}$ ).

When the interaction between age group and period was examined, between 1995 and 1999 the differences between older and younger people were large. For example, compared with 50-59 year olds the odds of those aged 80 or more receiving lipid lowering treatment was 0.05 (0.03 to 0.09). Between 2000 and 2005,

Table 2 |Odds ratio for association between lipid lowering drugs, antihypertensive or antithrombotic drugs*, and sex, Townsend fifth, and age

\begin{tabular}{|c|c|c|c|c|c|c|}
\hline \multirow[b]{3}{*}{ Variable } & \multicolumn{6}{|c|}{ Multivariable models $†$} \\
\hline & \multicolumn{2}{|c|}{ Lipid lowering drugs } & \multicolumn{2}{|c|}{ Antihypertensive drugs } & \multicolumn{2}{|c|}{ Antithrombotic drugs } \\
\hline & Odds ratio $(95 \% \mathrm{Cl})$ & P value $\ddagger$ & Odds ratio $(95 \% \mathrm{Cl})$ & $P$ value $\neq$ & Odds ratio $(95 \% \mathrm{Cl})$ & P valuef \\
\hline Men & 1 & \multirow{2}{*}{0.03} & 1 & \multirow{2}{*}{0.64} & 1 & \multirow{2}{*}{$<0.01$} \\
\hline Women & 0.88 (0.79 to 0.99$)$ & & 0.98 (0.88 to 1.08$)$ & & $0.85(0.75$ to 0.96$)$ & \\
\hline \multicolumn{7}{|l|}{ Townsend fifth: } \\
\hline $\begin{array}{l}\text { First (least } \\
\text { deprived) }\end{array}$ & 1 & \multirow{5}{*}{0.72} & 1 & \multirow{5}{*}{0.67} & 1 & \multirow{5}{*}{0.27} \\
\hline Second & 1.03 (0.87 to 1.21$)$ & & $1.03(0.91$ to 1.15$)$ & & $1.16(1.00$ to 1.34$)$ & \\
\hline Third & 0.94 (0.79 to 1.13$)$ & & 0.99 (0.86 to 1.13$)$ & & $1.14(0.97$ to 1.34$)$ & \\
\hline Fourth & 1.01 (0.76 to 1.32$)$ & & 1.05 (0.83 to 1.33$)$ & & 1.39 (1.03 to 1.88$)$ & \\
\hline $\begin{array}{l}\text { Fifth (most } \\
\text { deprived) }\end{array}$ & 0.98 (0.72 to 1.33$)$ & & 1.12 (0.87 to 1.45$)$ & & 1.41 (1.02 to 1.95$)$ & \\
\hline \multicolumn{7}{|l|}{ Age group: } \\
\hline $50-59$ & 1 & \multirow{5}{*}{$<0.001$} & 1 & \multirow{5}{*}{$<0.001$} & 1 & \multirow{5}{*}{$<0.001$} \\
\hline $60-69$ & 1.13 (0.96 to 1.34$)$ & & 1.41 (1.21 to 1.63$)$ & & 2.08 (1.79 to 2.41$)$ & \\
\hline $70-79$ & $0.86(0.70$ to 1.05$)$ & & $1.76(1.46$ to 2.11$)$ & & $2.87(2.27$ to 3.63$)$ & \\
\hline $80-89$ & 0.44 (0.33 to 0.59$)$ & & 1.53 (1.18 to 1.99$)$ & & 2.92 (2.09 to 4.09$)$ & \\
\hline$\geq 90$ & 0.12 (0.08 to 0.19$)$ & & 1.17 (0.87 to 1.57$)$ & & 2.38 (1.63 to 3.48$)$ & \\
\hline
\end{tabular}

Standard errors adjusted for clustering (113 practices); $n=12830$.

*Drugs prescribed within 0-90 days of incident stroke.

†Each risk factor (sex, Townsend fifth, age group) adjusted for other factors. $\ddagger$ Wald test. 
however, the gap had narrowed, although older people were still less likely to receive treatment: odds ratio for patients aged 80 or more 0.36 ( 0.28 to 0.46 ).

The odds of being prescribed antithrombotics, however, increased with increasing age. Thus compared with patients aged 50-59 the odds of patients aged 8089 receiving antithrombotics was 2.92 (2.09 to 4.09). The odds of being prescribed antihypertensives was also generally higher for older ages, with patients aged 70-79 having the highest chance of receiving such drugs (1.76, 1.46 to 2.11$)$.

There was evidence that women were less likely to receive lipid lowering drugs $(0.88,0.79$ to 0.99$)$ and antithrombotics $(0.85,0.75$ to 0.96$)$. The probability of receiving antihypertensives did not differ between the sexes. Finally, there was no evidence of a difference in the probability of receiving any of the three categories of drugs by socioeconomic circumstances.

When analyses were restricted to patients eligible to receive antihypertensives, there was evidence that patients in the most deprived fifth were more likely to receive antihypertensives $(1.43,1.03$ to 1.98$)$. The findings were not altered by adjusting for smoking status (see web extra table $\mathrm{D}$ ) or by expanding the treatment period.

\section{Secondary drug prevention and risk of mortality within first year}

In total, $10.4 \%$ of men and $12.5 \%$ of women died between 31 and 365 days after stroke (table 3). Univariable analyses showed that risk of mortality within the first year was associated with secondary drug prevention, age group, socioeconomic circumstances, and sex. The risk of mortality was lower in those who received secondary drug prevention (hazard ratio $0.38,95 \%$ confidence interval 0.31 to 0.46$)$, younger patients, and men. There was some evidence of an association with Townsend fifth $(\mathrm{P}=0.06)$. The multivariable analysis showed similar associations for receipt of secondary drug prevention $(0.50,0.42$ to 0.59 ), and with age and socioeconomic circumstances. Thus compared with 50-59 year olds, the risk of mortality increased with each decade: the hazard ratio among 60-69 year olds was 1.66 (1.24 to 2.23) and among 80-89 year olds was 5.63 (4.03 to 7.86). There was some evidence for different survival experiences by Townsend fifth. Compared with patients in the least deprived fifth, those in the most deprived fifth had an increased risk of mortality $(1.29,1.07$ to 1.55$)$. However, the adjusted risk of mortality by sex showed that women had a lower risk of mortality than men $(0.86,0.77$ to 0.96$)$. This was due to the presence of a larger proportion of women $(40.8 \%)$ than men $(23.0 \%)$ aged 80 or more with stroke. The findings were not altered when adjusting for liver disease (see web extra table $\mathrm{H}$ ), restricting the analyses to patients eligible to receive antihypertensives, expanding the treatment period, or adjusting for smoking status (see web extra table E). There was no evidence to indicate a violation of the proportional hazards assumption.
Effect of secondary drug prevention on risk of mortality within first year by age and sex

Analyses using the multivariable Cox proportional hazards model with interaction terms provided no evidence that the effect of treatment was modified by sex $(\mathrm{P}=0.76)$ or age $(\mathrm{P}=0.29)$. There was some evidence $(\mathrm{P}=0.02)$ of a modification by Townsend fifth. How ever there was no trend across the deprivation fifths.

Model based estimates of dying within one year suggested that, on average, patients receiving treatment had a $5.7 \%$ probability of death compared with $11.1 \%$ of patients not receiving treatment. These values changed little by sex and across Townsend fifths. Younger patients, because of their lower mortality rate, exhibited little absolute difference in mortality $(2 \%$ of treated patients compared with $3.9 \%$ of untreated patients among 50-59 year olds), whereas older patients exhibited a larger absolute difference $(10.5 \%$ of treated patients compared with $20 \%$ of untreated patients among $80-89$ year olds).

\section{DISCUSSION}

In this national study of nearly 13000 patients aged 50 years or more from 113 practices in primary care, we found low rates of receipt of secondary drug prevention: only $25.6 \%$ of men and $20.8 \%$ of women received treatment. We also found evidence of an association of reduced treatment with older age, with the odds of 80-89 year olds receiving secondary prevention nearly half that of 50-59 year olds. This was because older people were less likely to receive lipid lowering drugs (more so in the late 1990s than the early 2000s). This variation in treatment is important because the receipt of secondary drug prevention for patients who survived the first 30 days after a stroke was associated with a 50\% reduction in the hazard of dying during the first year. This reduction had different implications for different age groups as a result of the underlying increased rates of mortality for older people - that is, a $10.5 \%$ absolute difference in risk of mortality during the first year for 80-89 year olds compared with a $2.0 \%$ difference for 50-59 year olds. Crucially there was little evidence that the effect of treatment differed between the social groups examined.

We did, however, find some evidence for different survival experiences by Townsend fifth and sex that could not be explained by differences in treatment. The most socially disadvantaged patients had lower one year survival than their most advantaged counterparts, and women had a higher likelihood of one year survival than men. The findings were not altered by adjustment for smoking status or liver disease or extension of the prescription period.

\section{Strengths and limitations of the study}

We measured the relation between receipt of recommended combinations of drug treatments and one year mortality within primary care. The size of the beneficial effect of drug treatment combinations in routine clinical practice has not been previously shown. Meta-analyses of randomised controlled trials have 
established the effect of individual drugs for secondary prevention. ${ }^{36-38}$ However, treatment effects in routine clinical practice tend to be lower than in randomised trials (N Bennett and R Hooker, personal communication, 1996) and it cannot be assumed that all interventions have independent effects. ${ }^{39}$ A modelling exercise of the potential effectiveness of combining multiple interventions (including drugs, dietary modification, and exercise) estimated that at least $80 \%$ of recurrent strokes might be prevented by a comprehensive multifactorial approach. ${ }^{40}$ This estimate is similar to that which would be produced by Wald and Law's proposed "polypill" for vascular prevention. ${ }^{41}$ These approaches, however, also assumed that all interventions have independent effects and used estimates of treatment effects from randomised trials. By using the health improvement network dataset, which contains well recorded data on prescribing, we were able to establish the effect on one year survival of treatment in routine clinical practice and whether this varied between ages, sex, and socioeconomic circumstances. Use of this large dataset also enabled the calculation of precise effect estimates. All patients registered with a practice were included so selection bias should not be a problem. We excluded practices which did not fully use their computer system for consultations and those with inconsistent numbers of deaths for the practice for at least one year during the study period. We also excluded patients who did not meet the study inclusion criteria and those with missing Townsend scores. (The small numbers of patients with missing data on age and sex were excluded from the dataset before we received it.) In addition, the health improvement network database comprises general practices across England, enabling estimation of national trends overall as well as in different social groups.

The representativeness and the quality of data from the health improvement network has been compared with other databases. These show that when compared with the quality and outcomes framework, the health improvement network database contains nationally representative data for coronary heart disease and diabetes (BT Blak, M Thompson, and A Bourke. Ninth annual conference of the UK Federation of Primary Care Research Organisations, Liverpool, 2006). The health improvement network database produces similar results to the general practice research database when testing well established epidemiological associations between diseases and between diseases and drugs $^{42}$ and when detecting disease outcomes, ${ }^{43}$ and the baseline characteristics and levels of recording of cardiovascular risk factors are similar in the health improvement network and QResearch databases. ${ }^{44}$

However, our study also shares limitations of research using routinely collected data on patients. This includes non-standardised coding of date of diagnosis for incident stroke and non-standardised and incomplete coding of stroke subtype, comorbidity, management, and cause of death. Although we were able to examine the appropriateness of antihypertensive treatment, incomplete coding of stroke subtype and a lack of data on lipid levels meant that we were unable to assess patterns of prescribing by stroke type. This is relevant because experimental evidence suggests that lipid lowering drugs may not be indicated after haemorrhagic stroke. This research

Table $3 \mid$ Hazard ratio for association between mortality and sex, secondary drug prevention, Townsend fifth, and age

\begin{tabular}{|c|c|c|c|c|c|c|}
\hline \multirow[b]{2}{*}{ Variable } & \multirow[b]{2}{*}{ No of patients } & \multirow{2}{*}{$\begin{array}{l}\text { No }(\%) \text { of } \\
\text { deaths* }\end{array}$} & \multicolumn{2}{|c|}{ Univariable models } & \multicolumn{2}{|c|}{ Multivariable model $†$} \\
\hline & & & Hazard ratio $(95 \% \mathrm{Cl})$ & P value $\ddagger$ & Hazard ratio $(95 \% \mathrm{Cl})$ & P value $\neq$ \\
\hline Men & 6228 & $650(10.4)$ & 1 & \multirow{2}{*}{$<0.001$} & 1 & \multirow{2}{*}{$<0.01$} \\
\hline Women & 6602 & $823(12.5)$ & $1.22(1.10$ to 1.35$)$ & & $0.86(0.77$ to 0.96$)$ & \\
\hline \multicolumn{7}{|c|}{$\begin{array}{l}\text { Secondary drug } \\
\text { prevention: }\end{array}$} \\
\hline No & 9864 & $1322(13.4)$ & 1 & \multirow{2}{*}{$<0.001$} & 1 & \multirow{2}{*}{$<0.001$} \\
\hline Yes & 2966 & $151(5.1)$ & $0.38(0.31$ to 0.46$)$ & & $0.50(0.42$ to 0.59$)$ & \\
\hline \multicolumn{7}{|c|}{ Townsend fifth: } \\
\hline $\begin{array}{l}\text { First (least } \\
\text { deprived) }\end{array}$ & 3159 & $326(10.3)$ & 1 & \multirow{5}{*}{0.06} & 1 & \multirow{5}{*}{0.05} \\
\hline Second & 2829 & $344(12.2)$ & $1.20(1.02$ to 1.41$)$ & & $1.16(0.99$ to 1.36$)$ & \\
\hline Third & 2719 & 325 (11.9) & 1.18 (0.98 to 1.42$)$ & & 1.11 (0.93 to 1.32$)$ & \\
\hline Fourth & 2432 & $268(11.0)$ & $1.07(0.85$ to 1.35$)$ & & 1.07 (0.88 to 1.30$)$ & \\
\hline $\begin{array}{l}\text { Fifth (most } \\
\text { deprived) }\end{array}$ & 1691 & $210(12.4)$ & $1.22(1.00$ to 1.50$)$ & & 1.29 (1.07 to 1.55$)$ & \\
\hline \multicolumn{7}{|l|}{ Age group: } \\
\hline $50-59$ & 1639 & $54(3.3)$ & 1 & \multirow{5}{*}{$<0.001$} & 1 & \multirow{5}{*}{$<0.001$} \\
\hline $60-69$ & 2749 & $146(5.3)$ & 1.63 (1.22 to 2.18$)$ & & 1.66 (1.24 to 2.23$)$ & \\
\hline $70-79$ & 4319 & $407(9.4)$ & 2.95 (2.18 to 3.99) & & 2.99 (2.20 to 4.06$)$ & \\
\hline $80-89$ & 3387 & $586(17.3)$ & $5.78(4.23$ to 7.91$)$ & & $5.63(4.03$ to 7.86$)$ & \\
\hline$\geq 90$ & 736 & $280(38.0)$ & 14.99 (10.8 to 20.77$)$ & & 14.17 (9.91 to 20.26$)$ & \\
\hline
\end{tabular}

Standard errors adjusted for clustering (113 practices), $n=12830$.

*Deaths within 31-365 days of incident stroke.

†Each risk factor (sex, secondary drug prevention, Townsend fifth, age group) adjusted for other factors. $\ddagger$ Wald test. 
was, however, published after the period studied and so could not have influenced clinical decision making, ${ }^{45}$ (although observational evidence of the inverse association between serum cholesterol levels and haemorrhagic stroke was available during the period studied). Although the availability of data on stroke subtypes and lipid levels would have been valuable, haemorrhagic stroke occurs in a few patients with stroke so is unlikely to have had a major impact on our results. Had we been able to distinguish between subtypes, any social variations found in use of lipid lowering and antiplatelet drugs would have to be viewed in the context of differences in risk factors for the subtypes of stroke and social variations in the prevalence of these risk factors. ${ }^{18}$ Had we been able to take account of lipid levels in the analyses, this would not be expected to alter the age effects because of the high total cholesterol levels observed in men and women after age $45{ }^{3046}$ Inaccurate and missing data on blood pressure levels may also explain the results of our subgroup analyses for antihypertensive treatment. Only $221(1.72 \%)$ patients had a record of liver disease. This proportion of patients would not have been expected to have an impact on the results. Missing data may account for the small number of patients with recorded liver disease. A small retrospective analysis of primary care data from the United States suggests that the prevalence of chronic liver disease was $3.7 \%{ }^{47}$

Overall, $92 \%$ of patients had smoking status recorded within five years of stroke. The proportion of patients who were current smokers was lower than expected $(16.9 \%$ compared with $60 \%$ of patients who in other studies reported being current or former smokers). ${ }^{1648}$ This may be due, for example, to a smoker giving their smoking status as non-smoker. This potential misclassification could introduce bias, hence the results adjusted for smoking should be interpreted with caution. That said, the results after adjustment for smoking status are plausible; given the association of smoking with deprivation, ${ }^{49}$ adjustment for smoking would be expected to reduce any association between deprivation and stroke mortality. In this case there was no strong association between deprivation and mortality before adjustment and when we adjusted for smoking there remained no strong association.

Although data on cause of death were incomplete, data on all cause mortality were available. Such data are commonly used in preference to data on disease specific mortality because of known incompleteness and inaccuracies in recording cause of death and because other research has shown that the most common cause of death in the first year after stroke was the index stroke $(64 \%))^{50}$

Several other methodological issues need to be taken into account. Firstly, to limit overlap between treatment and outcome periods $(0-90$ days and 31-365 days, respectively), we decided to use the 90 day cut-off point for prescriptions in our main analysis. This minimised the possibility of immortal time bias or survival bias, which can lead to overestimation of treatment effect in epidemiological studies..$^{51}$ The remaining 60 day overlap between the treatment and outcome periods could nevertheless have led to some overestimation of treatment effects. Secondly, we used a well established method of assigning socioeconomic characteristics based on area of residence. This method rests on the assumption that people conform to the socioeconomic profile of their residential area. We do therefore recognise that misclassifications of individuals' socioeconomic circumstances can cause underestimates or overestimates of the relation between socioeconomic circumstances and treatment use and mortality. Thirdly, we confined our survival analyses to one year after stroke for analytical reasons. We used the Cox proportional hazards model, which assumes that the proportional effect of any variable on risk of mortality does not change over time. This assumption is not likely to hold over longer periods (more than one year) since the effect of treatment is maximal in the short term. However, this limitation is justified because the risk of death is greatest in the first year after stroke. Finally, we cannot assume that prescribing secondary drug prevention during the first year after stroke is maintained in the longer term.

\section{Comparison with other studies}

We found low rates of prescribing of effective secondary prevention in patients after stroke. Another analysis of English data (collected in south London during the 1990s) found higher treatment rates: $72.9 \%$ of patients considered appropriate for antithrombotics and $70.5 \%$ considered appropriate for antihypertensives actually received them. ${ }^{52} \mathrm{~A}$ strength of this study was its ability to classify the subtype of stroke. However, it was a small local study of 457 patients and limitations about misclassification of patients' appropriateness for preventive therapy were noted. A much larger study of nearly 45000 Canadian patients with stroke reported low rates of aspirin use (38.1\% in men and $35.6 \%$ in women). ${ }^{53}$ In another Canadian study of over 390000 patients aged 66 years or more and with a history of cardiovascular disease only $19.1 \%$ were prescribed statins. ${ }^{54}$

Although there is a considerable literature on social differences in treatment use across a diverse range of conditions, ${ }^{1213}$ few studies have examined care after stroke. The south London study examined management using antithrombotics and antihypertensives three months after ischaemic stroke. It found no associations between treatment use and age, social class, or sex.$^{52}$ It also failed to show significant differences in the recurrence free survival rate between patients who did and did not receive antithrombotics and antihypertensives after stroke. A much larger national study of prescribing lipid lowering drugs in primary care for coronary heart disease found a reduced likelihood of receiving such drugs with increasing age (as in our study) and in women. A weak socioeconomic gradient was also detected. ${ }^{55}$ In addition, a Swedish national study of patients after stroke found that, in 
common with our results, women received antithrombotics less often than men. ${ }^{56}$

Our results are in line with previous research, which has documented better one year survival in older women than in elderly men. ${ }^{535758}$ Other research has also found lower survival among socially disadvantaged groups. ${ }^{1459}$ The mechanisms through which socioeconomic circumstances affect stroke outcomes are unclear. Our findings of the lack of a social gradient in secondary prevention raises questions about the extent to which the social gradient can be explained by social variations in stroke severity (which is also socially patterned) and in the maintenance of unhealthy behaviours. A high prevalence of risk factors for stroke (blood pressure, smoking, diabetes, physical inactivity, obesity) in disadvantaged groups has been widely reported. ${ }^{14}$ However estimates vary as to how much of the difference in stroke outcome by socioeconomic circumstances can be accounted for by variations in prevalence of risk factors.

Other research that has tackled the question of the benefits of treatment among older people is in line with our findings. A meta-analysis of trials including patients aged 65 to 82 found that lipid lowering drugs reduce all cause mortality in elderly people. ${ }^{36}$ Extrapolation to older patients in the "real world" is supported by observational data, which showed that older patients attained a greater absolute risk reduction than younger patients. In addition, the incidence of adverse effects was similar in patients under 65 and over $65 .{ }^{6061}$ Moreover, the cost effectiveness ratio has been shown to be favourable in elderly people because they have a higher risk of mortality and morbidity. Finally, the magnitude of relative risk reduction for mortality or major morbidity was similar between the sexes.

\section{Implications and conclusions}

The enduring interest in McKeown's ideas can be explained by the ongoing relevance of the question that underlies them. This concerns the importance of medical interventions, compared with social, political, and economic measures on health status and inequalities in health. A large body of research suggests that broad measures to redistribute resources are required to improve health and reduce inequalities in health. ${ }^{62}$ However our findings on the contribution of medical care across population subgroups adds to the literature in this area, ${ }^{2-6}$ which suggests that medical interventions and social change should be viewed not as opposing choices but as complementing each other. ${ }^{1}$

It is reassuring that, in contrast with the evidence for other conditions, this national study of patients after stroke did not find that socially disadvantaged patients were less likely to receive treatment than their more affluent counterparts. Indeed, we report increased use of antiplatelets among certain social groups (older and more deprived patients). This is likely to be explained in part by the over the counter availability of aspirin for people who are not eligible for free prescriptions but can afford to pay.
Of more concern is the finding of under-use of lipid lowering therapies among elderly people. The low treatment rates may in part be explained by the fact that the first national clinical guidelines for stroke were not published until half way through the period under study. It may also be that doctors who care for patients with multiple comorbidities focus on these rather than on secondary prevention. However neither of these explanations account for the under-use of lipid lowering drugs only, which suggests that this may be due to the pressure that expensive lipid lowering drugs have on the primary care budget. Alternatively, variations in the use of evidence based therapies may be appropriate if they are secondary to variations in effectiveness, cost effectiveness, or the likelihood of adverse consequences and of adherence to treatment. It has been suggested that these factors may explain underuse in elderly people. ${ }^{63}$ Thus doctors may have concerns about the generalisability of results from clinical trial to older patients with comorbidities. However the relative survival benefits associated with lipid lowering drugs have been shown across multiple subgroups, including elderly patients. ${ }^{54}$ Furthermore, the rate of severe complications has been shown to be low. ${ }^{54}$ Doctors may also be reluctant to prescribe therapies to patients thought unlikely to adhere to treatment-for example, elderly patients exhibiting cognitive, functional, or social decline. However we found an increased likelihood of being prescribed antihypertensive and antiplatelet treatments with increasing age, so concerns about adherence to lipid lowering drugs alone are an unlikely explanation. Moreover, analysis of a database of British men with stroke found that concerns about adherence did not seem to explain low rates of medication ${ }^{64}$ and there is evidence of good compliance rates in elderly patients. ${ }^{65}$ Finally, lipid lowering drugs for secondary prevention in elderly people have been shown to be cost effective. ${ }^{66}$ Thus the evidence suggests that concerns about the trade-off between benefits and risks in elderly people may be exaggerated and that one year survival benefit is not modified by age. Therefore under-treatment of older people cannot be justified, unless it is explained by informed patient choice.

The delivery of effective secondary prevention after stroke is primarily the concern of primary care. Such inequalities must therefore be addressed if the UK government is to fulfil its commitment to reducing inequalities in health by improving access to primary care. Recent evidence suggests that the introduction of primary care performance indicators may contribute to the generation of more equitable health care. ${ }^{67}$

We thank the Longevity Steering Group for their valuable advice, comments, and support for this research, particularly John Bunker (University College London), Richard Wilkinson (University of Nottingham), Joseph Lu and Richard Humble (Legal and General), and Richard Willets (Willets Consulting); Martin Brown and Kate Walters (University College London) for their expert clinical input; and Mary Thompson (EPIC), Louise Marston (University College London), Andrew Hutchings (London School of Hygiene and Tropical Medicine), and Charlotte Ashton (Wandworth Primary Care Trust) for their advice. 


\section{WHAT IS ALREADY KNOWN ON THIS TOPIC}

Recent research on the contribution of medical care to population health has focused on the reduction in mortality from coronary heart disease

The contribution of medical care for other major conditions, including stroke, has, however, not been quantified

\section{WHAT THIS STUDY ADDS}

Patients aged over 80 are less likely to receive secondary drug prevention after stroke than younger patients

Evidence suggested that women were less likely to receive treatment than men but that socioeconomic status was not associated with differences in treatment

Under-treatment of older people cannot be justified in terms of variations in effectiveness because older people are at least as likely to benefit from treatment as younger people

Contributors: The idea for the research originated at the Longevity Steering Group (of which RR,MB, DB, are members). The study was led by $R R$, who is guarantor for the paper. RR, GA, SH, IP, RM, MB, and DB participated in the study design and analysis and interpretation of results. GA and SH led the statistical analysis. WW undertook the analysis. All authors drafted the article and approved the final version. Funding: RR is partly funded by a National Institute for Health Research public health career scientist award and by the National Institute for Health Research University College London Hospital/University College London Comprehensive Biomedical Research Centre. WW is funded by Legal and General Group. The research was funded in part by the actuaria profession (Institute of Actuaries in England and Wales and the Faculty of Actuaries in Scotland). The authors' work was independent of the funders.

Competing interests: None declared.

Ethical approval: This study was approved by the London research ethics committee, National Research Ethics Service (07/MRE02/19).

1 Colgrove J. The McKeown thesis: a historical controversy and its enduring influence. Am / Public Health 2002;92:725-9.

2 Hunink MG, Goldman L, Tosteson AN, Mittleman MA, Goldman PA, Williams LW, et al. The recent decline in mortality from coronary heart disease, 1980-1990: the effect of secular trends in risk factors and treatment. JAMA 1997;277:535-42.

3 Capewell S, Morrison CE, McMurray JJ. Contribution of modern cardiovascular treatment and risk factor changes to the decline in coronary heart disease mortality in Scotland between 1975 and 1994. Heart 1999;81:380-6.

4 Unal B, Critchley J, Capewell S. Explaining the decline in coronary heart disease mortality in England and Wales, 1981-2000. Circulation 2004;109:1101-7.

5 Capewell S, Beaglehole R, Seddon M, McMurray J. Explaining the decline in coronary heart disease mortality in Auckland, New Zealand between 1982 and 1993. Circulation 2000;102:1511-6.

6 Unal B, Critchley J, Capewell S. Modelling the decline in coronary heart disease deaths in England and Wales, 1981-2000: comparing contributions from primary prevention and secondary prevention. BMJ 2005;331:614.

7 Willets RC, Gallop AP, Leandro PA, Lu JLC, Macdonald AS, Miller KA, et al. Longevity in the 21st century. Br Actuar / 2004:10:685-832.

8 Office for National Statistics. Expectation of life at birth and selected ages (table 5.1). Health Stat $Q$

2003;20:55. Available at www.statistics.gov.uk

9 Bond M, Bowling A, McKee D, Kennelly M, Banning AP, Dudley N, et al. Does ageism affect the management of ischaemic heart disease? J Health Serv Res Policy 2003;8:40-7.

10 Bowling A, Bond M, McKee D, McClay M, Banning AP, Dudley N, et al. Equity in access to exercise tolerance testing, coronary angiography, bypass grafting by age, sex and clinical indications. Heart 2001;85:680-6.

11 Monette I, Gurwitz JH, Rochon PA, Avorn J. Physician attitudes concerning warfarin for stroke prevention in atrial fibrillation: results of a survey of long-term care practitioners. J Am Geriatr Soc 1997;45:1060-5.

12 Dixon A, Le Grand I, Henderson J, Murray R, Poteliakhoff E. Is the British national health services equitable? The evidence on socioeconomic differences in utilization. J Health Serv Res Policy 2007;12:104-9.

13 Raine R. Does gender bias exist in the use of specialist health care? Health Serv Res Policy 2000;5:237-49.
14 Cox AM, McKevitt C, Rudd AG, Wolfe CDA. Socioeconomic status and stroke. Lancet Neurology 2006;5:181-8.

15 Carroll K, Murad S, Eliahoo J, Majeed A. Stroke incidence and risk factors in a population-based prospective cohort study. Health Stat $Q$ 2001;12:18-26.

16 Hajat C, Dundas R, Stewart J, Lawrence E, Rudd A, Howard R, et al. Cerebrovascular risk factors and stroke subtypes. Stroke 2001;32:37-42.

17 Kunitz SC, Gross CR, Heyman A, Kase CS, Mohr JP, Price TR, et al. The pilot stroke data bank: definition, design, and data. Stroke 1984;15:740-6.

18 Lawlor DA, Smith GD, Leon DA, Sterne JAC, Ebrahim S. Secular trends in mortality by stroke subtype in the 20th century: a retrospective analysis. Lancet 2002;360:1818-23.

19 Hart CL, Hole DJ, Smith GD. The relation between cholesterol and haemorrhagic or ischaemic stroke in the Renfrew/Paisley study. J Epidemiol Community Health 2000;54:874-5.

20 Shinton R, Beevers G. Meta-analysis of relation between cigarette smoking and stroke. BMJ 1989;298:789-94.

21 Ariesen MJ, Claus SP, Rinkel GJE, Algra A. Risk factors for intracerebra hemorrhage in the general population: a systematic review. Stroke 2003;34:2060-5.

22 Bourke A, Dattani H, Robinson M. Feasibility study and methodology to create a quality-evaluated database of primary care data. Inform Prim Care 2004:12:171-7.

23 Davies AR, Smeeth L, Grundy EM. Contribution of changes in incidence and mortality to trends in the prevalence of coronary heart disease in the UK: 1996-2005. Eur Heart J 2007;28:2142-7.

24 Townsend $\mathrm{P}$, Phillimore $\mathrm{P}$, Beattie $\mathrm{A}$. Inequalities in health in the northern region. Newcastle upon Tyne: Northern Regional Health Authority and University of Bristol, 1986.

25 Maguire A, Blak BT, Thompson M. The importance of defining periods of complete mortality reporting for research using automated data from primary care. Pharmacoepidemiol Drug Saf 2009;18:76-83.

26 Robinson D, Wanger K, Price C. The clinical terms and IPCC: identifying equivalence and enabling compatibility for "non-medical" terms. Proceedings of the annual conference of the Primary Health Care Specialist Group 1998. Worcester: British Computer Society, 1998.

27 Intercollegiate Working Party for Stroke. National clinical guidelines for stroke, 2nd ed. London: Royal College of Physicians of London, 2004.

28 PROGRESS Collaborative Group. Randomised trial of a perindoprilbased blood-pressure-lowering regimen among 6105 individuals with previous stroke or transient ischaemic attack. Lancet 2001;358:1033-41.

29 Shepherd J. Who should receive a statin these days? Lessons from recent clinical trials. J Intern Med 2006;260:305-19.

30 Banks J, Breeze E, Lessof C, Nazroo J, eds. Retirement, health and relationships of the older population in England: the 2004 English Longitudinal Study of Ageing. London: Institute for Fiscal Studies, 2006.

31 British Medical Association, Royal Pharmaceutical Society of Great Britain. British national formulary. London: BMA, RPS, 2007. (No 53.)

32 British Medical Association, Royal Pharmaceutical Society of Great Britain. British national formulary. London: BMA, RPS, 2008. (No 56.)

33 National Institute for Health and Clinical Excellence. Chronic kidney disease: early identification and management of chronic kidney disease in adults in primary and secondary care. 2008. (Clinical guideline 73.) www.nice.org.uk/CG73.

34 McKevitt C, Coshall C, Tilling K, Wolfe C. Are there inequalities in the provision of stroke care? Analysis of an inner-city stroke register. Stroke 2005;36:315-20.

35 Intercollegiate Stroke Working Party. National sentinel stroke audit 2004: concise reports. London: Royal College of Physicians of London, 2005.

36 Afilalo J, Duque G, Steele R, Jukema JW, de Craen AJM, Eisenberg MJ. Statins for secondary prevention in elderly patients. J Am Coll Cardio 2008;51:37-45.

37 Antithrombotic Trialists' Collaboration. Collaborative meta-analysis of randomised trials of antiplatelet therapy for prevention of death, myocardial infarction, and stroke in high risk patients. $B M$ 2002;324:71-86.

38 Gueyffier F, Boissel J-P, Boutitie F, Pocock S, Coope J, Cutler J, et al. The INDANA Project Collaborators. Effect of antihypertensive treatment in patients having already suffered from stroke. Stroke 1997; 28:2557-62

39 Rothwell PM. Making the most of secondary prevention. Editorial. Stroke 2007;38:1726.

40 Hackman DG, Spence JD. Combining multiple approaches for the secondary prevention of vascular events after stroke: a quantitative modeling study. Stroke 2007;38:1881-5.

41 Wald NJ, Law MR. A strategy to reduce cardiovascular disease by more than $80 \%$. BMJ 2003;326:1419-23. 
42 Lewis JD, Schinnar R, Bilker WB, Wang X, Strom BL. Validation studies of the health improvement network (THIN) database for pharmacoepidemiology research. Pharmacoepidemiol Drug Saf 2007;16:393-401.

43 Garcia Rodriguez LA, Barreales Tolosa L. Risk of upper gastrointestinal complication among users of traditional NSAIDs and COXIB in the general population. Gastroenterology 2007;132:498-506.

44 Hippisley-Cox J, Coupland C, Vinogradova Y, Robson J, Brindle P. Performance of the QRISK cardiovascular risk prediction algorithm in an independent UK sample of patients from general practice: $a$ validation study. Heart 2008;94:34-9.

45 The Stroke Prevention by Aggressive Reduction in Cholesterol Levels (SPARCL) Investigators. High-dose atorvastatin after stroke or transient ischemic attack. N Engl J Med 2006;355:549-59.

46 National Centre for Social Research. Health survey for England. London: Department of Health, 2004.

47 Navarro VJ, Louis TS, Bell BZ, Sofair AN. Chronic liver disease in the primary care practices of Waterbury, Connecticut. [Letter.] Hepatology 2003;38:1062.

48 Di Carlo A, Lamassa M, Baldereschi M, Pracucci G, Basile AM, Wolfe $C D$, et al. Sex differences in the clinical presentation, resource use, and 3-month outcome of acute stroke in Europe: data from a multicenter multinational hospital-based registry. Stroke 2003;34:1114-9.

49 Lyratzopoulos G, Heller RF, McElduff P, Hanily M, Lewis P. Deprivation and trends in blood pressure, cholesterol, body mass index and smoking among participants of a UK primary care-based cardiovascular risk factor screening programme: both narrowing and widening in cardiovascular risk factor inequalities. Heart 2006;92:1198-206.

50 Hankey GJ, Jamrozik K, Broadhurst RJ, Forbes S, Burvill PW, Anderson CS, et al. Five-year survival after first-ever stroke and related prognostic factors in the Perth Community Stroke Study. Stroke 2000;31:2080-6.

51 Zhou Z, Rahme E, Abrahamowicz M, Pilote L. Survival bias associated with time-to-treatment initiation in drug effectiveness evaluation: a comparison of methods. Am J Epidemiol 2005;162:1016-23.

52 Hillen T, Dundas R, Lawrence E, Stewart JA, Rudd AG, Wolfe CD. Antithrombotic and antihypertensive management 3 months after ischemic stroke: a prospective study in an inner city population. Stroke 2000;31:469-75.

53 Holroyd-Leduc JM, Kapral MK, Austin PC, Tu JV. Sex differences and similarities in the management and outcome of stroke patients. Stroke 2000;31:1833-7.
54 Ko D, Mamdani M, Alter D. Lipid lowering therapy with stains in high risk elderly patients: the treatment paradox. JAMA 2004:21:1864-70.

55 DeWilde S, Carey IM, Bremner SA, Richards N, Hilton SR, Cook DG. Evolution of statin prescribing 1994-2001: a case of agism but not of sexism? Heart 2003;89:417-21.

56 Glader E-L, Stegmayr B, Norving B, Terent A, Hulter-Asberg K, Per-Olov W, et al. Sex differences in management and outcome after stroke. A Swedish national perspective. Stroke 2003;34:1970-5.

57 Jiang Y, Sheikh K, Bullock C. Is there a sex or race difference in stroke mortality? / Stroke Cerebrovasc Dis 2006;15:179-86.

58 Griffiths C, Brock A. Twentieth century mortality trends in England and Wales. Health Stat Q 2003;18:5-17.

59 Arrich J, Lalouschek W, Mullner M. Influence of socioeconomic status on mortality after stroke: retrospective cohort study. Stroke 2005;36:310-4.

60 Hunt D, Young P, Simes J, Hague W, Mann S, Owensby D, et al. Benefits of pravastatin on cardiovascular events and mortality in older patients with coronary heart disease are equal to or exceed those seen in younger patients: results from the LIPID trial. Ann Intern Med 2001;134:931-40.

61 LaRosa JC, Applegate W, Crouse JR 3rd, Hunninghale DB, Grimm R, Knopp R, et al. Cholesterol lowering in the elderly. Results of the Cholesterol Reduction in Seniors Program (CRISP) pilot study. Arch Intern Med 1994;154:529-39.

62 Wilkinson RG. The impact of inequality: how to make societies healthier. London: Routledge, 2005.

63 Alter DA, Manuel DG, Gunraj N, Anderson G, Naylor CD, Laupacis A Age, risk-benefit trade-offs, and the projected effects of evidencebased therapies. Am J Med 2004;116:540-5.

64 Ramsay SE, Whincup PH, Wannamethee SG, Papacosta O, Lennon L, Thomas MC, et al. Missed opportunities for secondary prevention of cerebrovascular disease in elderly British men from 1999 to 2005: a population-based study. J Public Health 2007;29:251-7.

65 Jackevicius CA, Mamdani M, Tu JV. Adherence with statin therapy in elderly patients with and without acute coronary syndromes. JAMA 2002;288:462-7.

66 Ward S, Lloyd Jones M, Pandor A, Holmes M, Ara R, Ryan A, et al. A systematic review and economic evaluation of statins for the prevention of coronary events. Health Technol Assess 2007;11:1-160,iii-iv.

67 Ashworth M, Medina J, Morgan M. Effect of social deprivation on blood pressure monitoring and control in England: a survey of data from the quality and outcomes framework. BMJ 2008;337:a2030.

Accepted: 16 January 2009 